\title{
Creating Pathway for Enhancing Student Collection of Academic Records in Nigeria - a New Direction
}

\author{
Ugochukwu Onwudebelu, ${ }^{1, *}$, Sanjo Fasola ${ }^{2}$, Eweje Oluwafemi Williams ${ }^{2}$ \\ ${ }^{1}$ Department of Computer Science, Federal University Ndufu-Alike Ikwo (FUNAI), P.M.B. 1010, Abakaliki, Ebonyi State, Nigeria \\ ${ }^{2}$ Department of Computer Science,University of Ibadan, Ibadan, Nigeria \\ *Corresponding Author: Anelectugocy@yahoo.com
}

Copyright (C) 2013 Horizon Research Publishing All rights reserved.

\begin{abstract}
Education is priceless and every academic institution needs to be very serious about its management and administration in order not to mess around with the students' academic headway. Therefore, there is need for them to significantly improve and incredibly convenient arrangement by which former students receive final academic transcripts. It is indeed a nightmare of unimaginable proportions to attempt to get academic records from some universities, especially in recent times. This is as a result of the administrative heedlessness of some record officials in the university. A request for an undergraduate transcript means the requestor sometime is expected to wait longer than expected with the hope of getting his results. This paper proposes a Transcript Xpress which will open new and convenient routes to key educational solutions to information, providing application service delivery and ensure that proper records are kept in tact. This will improve the university's efficiency and effectiveness through the provision of high quality information system and services. Transcript Xpress will be the catalyst for change through improved educational solutions.
\end{abstract}

Keywords Nigeria, E-transcript, Academic Record, Student, Quality Control, Education

\section{Introduction}

The need for transcript for further studies is becoming more ramparts since many universities need current and final transcripts while other universities may only need those final transcripts of students who have been accepted. In respect with the academic transcripts, today in our country it is very hard and very slow to process an academic transcript, especially in the state universities as well as very slow to transfer academic transcripts to other educational institutions. Furthermore, it consumes much time, like between ten months and four years to process and transfer the academic transcripts to another institutions. But in developed country, like in the United States of America (USA), it takes a day to a week to send out an academic transcript to other schools.
Many academic and non academic staffs are still ignorant of the negative consequences of delaying the students' academic transcripts. One of the unintended consequences of these difficulties is that some have taken to forging documents, knowing full well forging documents is a crime. Therefore, there is a need for universities to computerize all their records and update their systems to eradicate all delays resulting in sending supporting documents to enable students achieve their academic goals.

Since transcripts are an official record of a student's work, showing courses taken and grades obtained, it is essential and recommendable that the universities should respond appropriately to their former students' request for this all-important document. The late processing of students' transcript is affecting the nation as well, take for example an engineering student who wants to improve his engineering skills and profile so that he would be more able and capable to increase our nation's engineering productivity will be denied and frustrated by transcript delays. One of the reasons for such delays in transcript delivery is as result of poor record keeping and retrieval. Unfortunately, the emotional and economic cost of this challenge is rather incalculable: lost opportunities for further studies and good employment to mention just two. It is regrettable that many prospective graduate students have lost admission opportunities within and outside Nigeria as a result of their inability to obtain their transcripts to support their applications on time. We therefore view this matter as a serious national problem and to address it with the seriousness it deserves.

In some cases, students have had to pay the fees twice and use multiple contacts to secure the transcript, for instance, students who have travel overseas need the intervention of friends and relatives to obtain their academic records and this will involve travelling very long distances. Thus, the sole purpose of securing the school documents becomes worrisome, stressful and time consuming. There is no guarantee that the transcript would be secured in the first, second, fifth or sixth attempt. If the transcripts arrived it arrives with errors or incomplete, that is, partial transcript was sent. All Nigerian universities must ensure proper 
records are kept and adding electronic records to their paper records is a viable option. Aside from the official fee to be paid to the school, facilitators within the school system might also need to be paid. Moreover, friends and relatives who spent their time going back and forth must also be compensated. Transcript (and postage) that ordinarily should cost no more than $\$ 50$ may end up costing the requester upward of $\$ 200$. And indeed, there is no guarantee that the requested documents will arrive, or arrive in a timely fashion. Such is the frustration of obtaining transcript from some Nigerian institutions of higher learning.

Many admissions in the Nigeria universities have been administered on papers over the years and students records are kept in file in which over the years are liable to wear and tear. Many of such files are also liable to misplacement, rusting etc. It becomes a difficult thing to produce transcript as early as a student will expect which has made them to miss many opportunities such as oversea learning, job opportunities and promotion in their respective work places. In a bid to provide solution to such problems, computerizing such documents will be of help in many ways. This will help in keeping the records for a long time without any alteration and for easy retrieval of records. We have come up with a fast way of computerizing the students' records since the inception by first digitizing the records; capture the data into the database for transcript processing.

\subsection{Timing Issues: Delayed Transcripts from Universities}

An attempt to secure academic transcripts from any Nigerian university or from other institutions of higher learning is full of challenges. And in fact, such difficult experiences are not limited to schools. Procuring medical records, police records/clearance or government documents can also be an uphill task. Although securing documents and transcripts may be easier if you live in Nigeria; attempting to do so from abroad can be annoying, traumatic and time consuming. The late process or transfer of the academic transcripts to other academic institution can sometime be attributed to poor management, poor administrative policy and procedure. There are lots of graduates who completed either the bachelor's degrees or the graduate programs in Nigeria, before relocating to USA. Today, these particular university graduates are confused of their goals academically in the USA because of long waiting of their transcripts process from the universities in Nigeria. This project is bent at making things easier for students. One of the goals is to make it as easy and inexpensive as possible for both students and universities.

This problem is very common, thus delaying their pursuit of their dreams in the foreign countries, they have migrated to. How many graduates have failed to secure employment or graduate school admission all because institutions failed to send complete and correct transcript in a timely manner? How many dreams have been cut short by the actions and inaction of these institutions or officers within those institutions? Millions of graduates have suffered untold hardship, humiliation, mockery and deprivation as a result of their inability to retrieve their transcripts from home. Although the Nigerian Universities System Database (NUCDB) has as one of the many goals to automate standard transcript generation system for each university, it is yet to fully actualize it. Presently, NUCDB is at the stage of providing full student bio data and course registration, management of minimum and maximum course unit per student etc with University of Uyo making history as the first Nigerian university to implement the newly agreed NUCDB system [7].

\subsection{What is a Record?}

Records [14] include all books, papers, maps, photographs, machine readable materials, or other documentary materials, regardless of physical form or characteristics, made or received by an agency as well as preserved or appropriate for preservation by that agency or its legitimate successor as evidence of the organization, functions, policies, decisions, procedures, operations, or other activities of the Government or because of the informational value in them. Several key terms, phrases, and concepts in this definition of records are defined as follows [14]:

1. Documentary materials is a collective term for records, non-record materials, and personal papers that refers to all media containing recorded information, regardless of the nature of the media or the method(s) or circumstance(s) of recording.

2. Regardless of physical form or characteristics means that the medium may be paper, film, disk, or other physical type or form; and that the method of recording may be manual, mechanical, photographic, electronic, or any other combination of these or other technologies.

3. Made means the act of creating and recording information by agency personnel in the course of their official duties, regardless of the method(s) or the medium involved. The act of recording is generally identifiable by the circulation of the information to others or by placing it in files accessible to others.

4. Received means the acceptance or collection of documentary materials by agency personnel in the course of their official duties regardless of their origin (for example, other units of their agency, private citizens, public officials, other agencies, contractors, Government grantees) and regardless of how transmitted (in person or by messenger, mail, electronic means, or by any other method).

5. Preserved means the filing, storing, or any other method of systematically maintaining documentary materials by the agency. This term covers materials not only actually filed or otherwise systematically maintained but also those temporarily removed from existing filing systems.

6. Appropriate for preservation means documentary materials made or received which in the judgment of the agency should be filed, stored, or otherwise systematically maintained by an agency because of the evidence of agency 
activities or information they contain, even though the materials may not be covered by its current filing or maintenance procedures.

In [15] Daramola classified records as follows:

a) Reference Records: Policy records which must be possessed by a school which contains Government policies, decisions of governing council, and procedures on funding and moral codes.

b) Administrative Records: Includes records of great visits, events, annual enrolment of students and records of personnel that have served and still serving in an organization.

c) Academic Records: Include records of curriculum issues, facilities and equipment for teaching and learning guidelines for the introduction of new academic programmes and students' academic records. Others include official correspondence and financial management records.

In summary records must exhibit the following characteristics:

i. Records must be complete if they are kept regularly.

ii. Records must be honestly kept.

iii. Records must be retrievable.

iv. Records must be useable.

v. Records must be backed up by original documents.

\section{Literature Review}

Not much has been written on academic transcript in Nigeria. However, Fabunmi and Isah in [4] studied and investigated the determinant factors involved in planning a good records retrieval system in a university environment. Specifically, their studies seek to identify the factors that inhibit effective document/records storage and retrieval in universities in Nigeria and thus proffer solutions to effectively address the problem. In [2] Black explained how an e-transcript will mark the end of paper transcript and how a secured electronic transcript can be produced with partnership with Avow systems [3].

In [9] Egwunyenga examined the problems and management options of record keeping among universities in the South-West geo-political zone of Nigeria. Her findings revealed that negative attitude of staff, improper security of records, inadequate computer terminals, ineffective means of retrieving records, lack of record keeping policy, inadequate resources as well as lack of record retention and disposition schedule among others were identified as the associated problems. As a result, the following recommendations were made: only professionally trained staff in records management be employed over time and/or existing staff be sent for necessary training through in-service programmes. Induction programmes for new staff and refresher courses for old staff were also recommended as well as a full computerization of all records.

In [10] Nakpodia looked critically on the challenges on students' records in tertiary institutions in Nigeria. Unlike [9] Nakpodia the study used samples from Federal, State and Private Universities in the South-South geo-political zone of
Nigeria. The findings revealed that the challenge encountered in the management of records was common to Federal, State and Private Universities in Nigerian. In [13], Iwhiwhu et al, discussed the management of staff records at Delta State University Library, Abraka, Nigeria. However, nothing concerning students' academic record was mentioned, rather they concentrated in management of staff records in the library. While Olagboye, in his book [12], listed the following as school records:

a) A register of admission and withdrawal

b) A register of attendance

c) A log-book

d) A cash book

e) A visitor's book

f) A copy of education law

g) Scheme of work

h) Teacher's record of work

i) School time-table

j) Corporal punishment book

k) Counterfoils of transfer and leaving certificates, and Minutes book of the Board of Governors.

Although, the subject matter of this paper is academic records, nevertheless, school records serve as a bank in which information is deposited and kept with the hope of retrieving and utilizing in the future. Proper keeping of school records [11] could enhance planning process, serve as historical record, provide knowledge on students' academic performance and facilitate schools' financial administration. It will also provide a basis for advisory and counseling services.

\section{Transcript Xpress}

Transcript Xpress (TX) is thus aimed at changing the way the university community communicates and exchanges information by: centralizing information environment for administration and academic services and replacing obsolete and time-consuming paper forms with modern web electronic forms. Our target audience is academic institutions aiming to remain at the forefront of technology by utilizing the most user-friendly and cost-effective pathway to act as an interface between the universities and the students. Transcript Xpress main goal was to develop and implement a web-based paperless communication environment for students, faculty and staff. Most academic institutions face mounting technical and fiscal challenges to stay at the forefront of technology. These challenges require the development of technology that is flexible, expandable, easily maintained, and, of course, cost- efficient. Transcript Xpress is able to respond to those concerns. We would act as an interface between the institution and the students. In other to achieve this purpose TX does that in four stages:

a) Digitizing Of All Documents

b) Quality Control from the University

c) Student Transcript Requests

d) Delivery Method

\subsection{Digitizing Of All Documents}


The worn out students' document data are extracted and digitized [5], then routed to an archive, database. ReadSoft scanner [8] has a powerful recognition engines and image enhancement features to ensure quick, accuracy and prevent fraudulent manipulation, while reducing or eliminating the need for manual entry. It automates document processing functions previously done manually, cutting costs while speeding the flow and improving the accuracy of information. Taken University of Ilorin as example, current students and ex-students who graduated after 1986 will have their records transform into electronic forms and store in a database. Application program to interface the database for easy retrieval of records was developed which will ease future transcript generation.

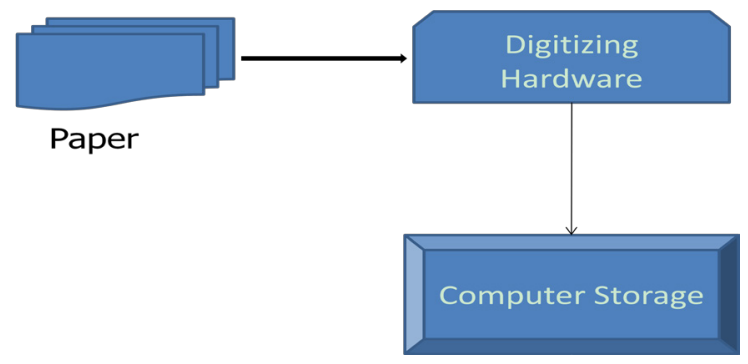

Figure 1. Digitizing old Dirty and Dusty Students' Records

We ensured the use of robust database with high level of security and protection from phishing and hackers.

Scanning software [6] is used to capture, sort and index a large volume of documents and pulling the documents together and dropping them straight into each departmental queue (database). Thus by so doing we save thousands of hours otherwise wasted by searching for documents, data and prioritizing work. The detailed indexing will help the document management system for effective searching. In summary the TX officials does the following: digitize all paper records and capture them into the system, extract all needed information from the digitized images, arrange the record into the database and develop application for record retrieval.

\subsection{Quality Control from the University}

In other to prevent fraudulent manipulation of students' academic records as it is being digitized the TX officials and the Registrar's Office of university in question need to carry quality control to ascertain if the content in the electronic forms is identical to the one on the old torn, dirty and dusty students' record. The quality control section is to ensure that the validity, authenticity, and the contents of the document have not been altered. The university Registrar must certify that the data in the electronic forms is a complete and accurate record of the university. Any document with an invalid display such as errors or omissions should be rejected and corrected by TX team. The TX officials and the university official will carry out two quality control measures as shown in Figures 3 and 4 below.

INCOMING FORMS

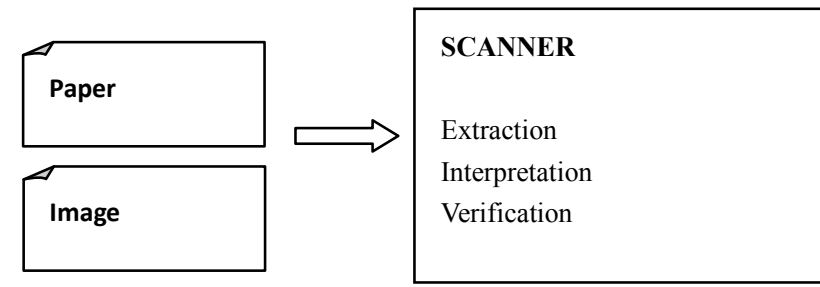

Figure 2. A Complete Forms Processing Solution

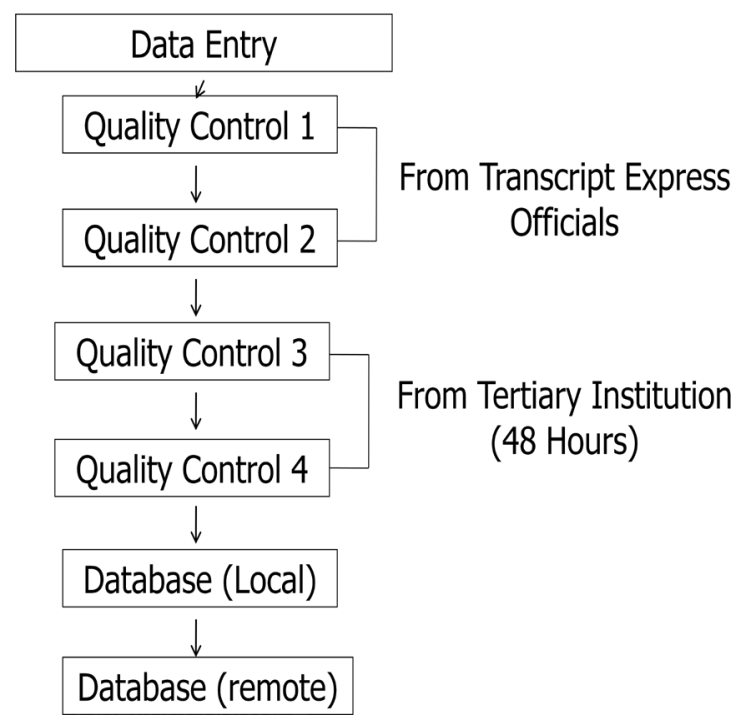

Figure 3. Quality Control by TX and Institution Officials 


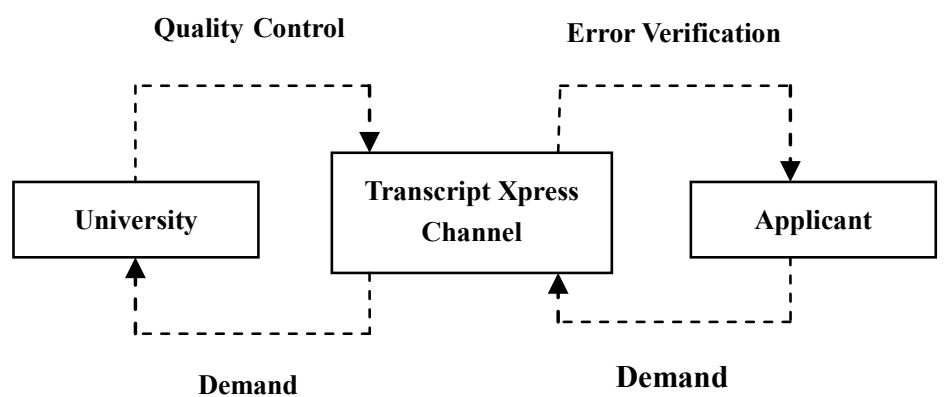

Figure 4. Transcript Xpress Strategy

\subsection{Student Transcript Requests}

Financial obligations to the University must be cleared before requests can be honored. Students are welcome to visit the TX site and request a transcript, either paper or electronic (future work - see Figure 7). The TX team provides a transcript request form which must be completed online. The requestor will be expected to provide the following information in the transcript request form: requestors' name as it appear on the certificate, mode of entry, mailing address of the recipient or destination institutions, requestor e-mail address, date of birth, matriculation number, department, faculty, telephone number etc. (see Figure 5 and 6 )

\subsubsection{Student Notification}

Once the Registrar's Office has processed the request TX will send the recipient e-mails. These transcripts are considered official documents and can be validated because they have been signed, sealed and certified by the requestor's alma mater. For each transcript requested and mailed, it is embedded in sealed envelope. This is very essential because destination institutions and embassies issuing relevant visas nowadays cross-check the authenticity of documents with the issuing universities. Requests will usually be processed within three to five business days of receipt. Students will receive two notification e-mails from Transcript Xpress: the first, when the transcript has been sent to the designated recipient by TX and the second will confirm that student's identified recipient has received the official transcript. If the first e-mail notification is not received, the student should make sure the notification was not intercepted by a spam filter and consequently they check spam folder.

\subsection{Delivery Methods}

Paper transcript would not go away right away any time soon. They are universal and have been tested in court. We will produce a printed copy of the student's transcript and deliver it to the authorized delivery agent selected by the requestor such as DHL, EMS, Errand Express, TPOST, FedEx etc. In our next work we intend to move to "paperless" transcript in Nigeria. This is because more foreign organizations are insisting on electronic documents and are not willing to accept paper documents as delivery is within minutes of the request being processed. The requestor should allow three to five business days for paper transcript processing as mentioned above. For now we do not expedite transcript requests for electronic universities. Once the requestor's transcript has been delivered he/she will be notified of delivery as stated above.

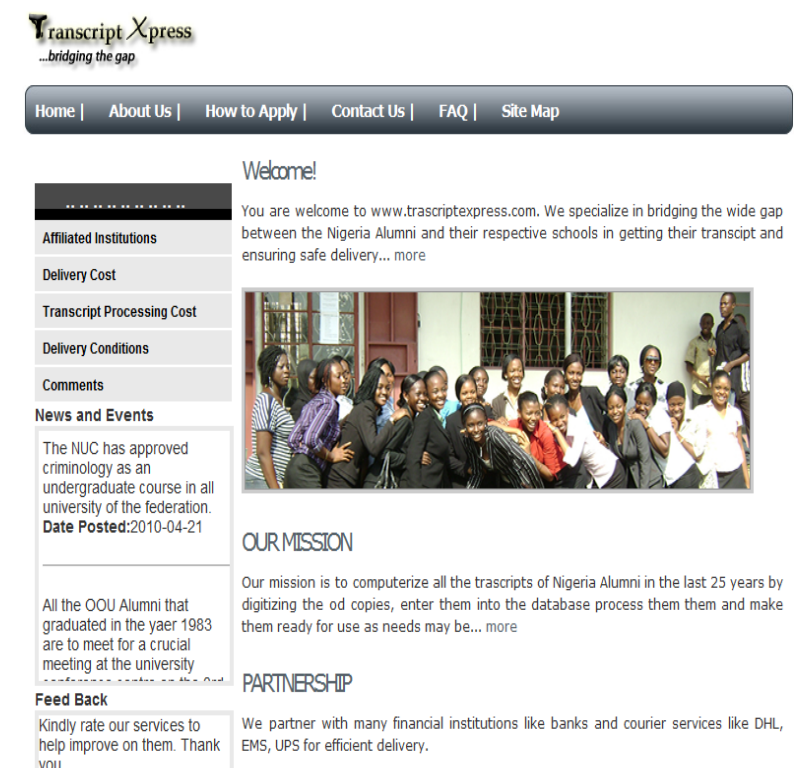

Figure 5. Transcript Xpress Home Page

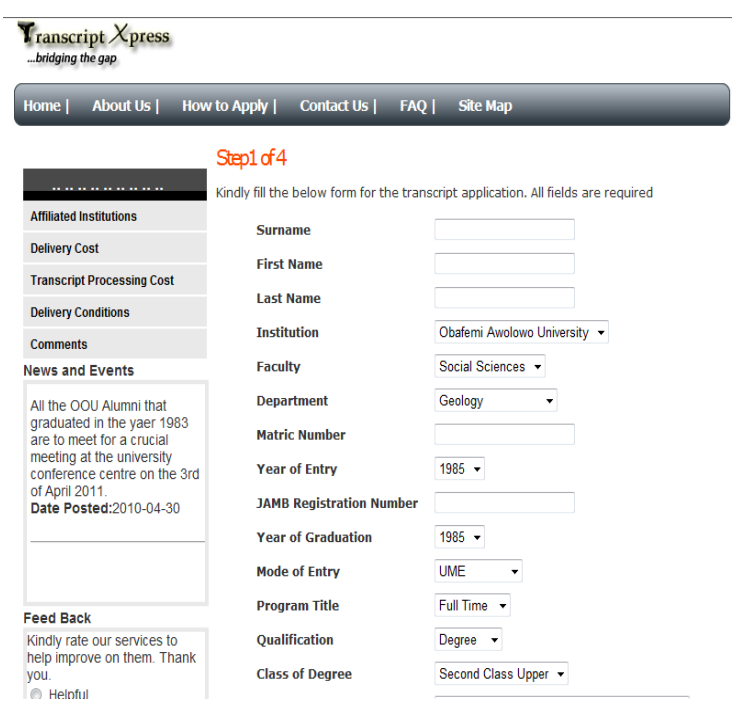

Figure 6. Transcript Xpress Request Form 


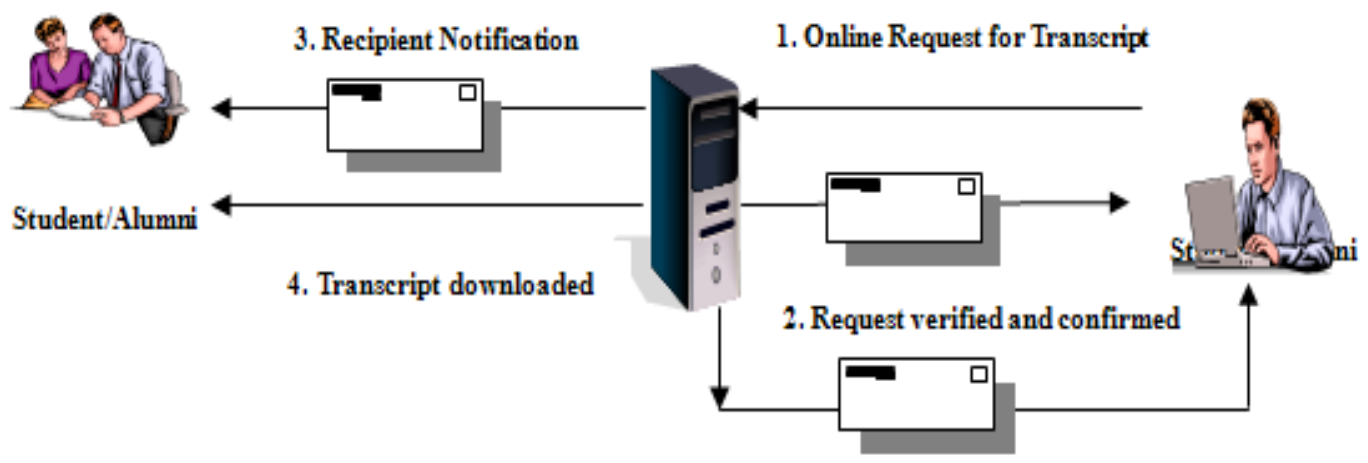

5. Download Confirmation

Figure 7. A Completely Electronic Transcript from Order to Payment to Delivery

\section{Conclusion}

TX will bring one of the most innovative and cost effective web technologies to academic institutions across Nigeria. Nevertheless, for the development and the growth of our nation in regard to education means that the process of the academic transcripts would be made as easy as it is in the United States of America. Academic institutions' dependence on web-based technologies to improve efficiency in class offerings, academic records, and office documentation is increasing at a rapid pace. The resource constraints of most academic institutions require that the technology be flexible, expandable, easily maintained, and cost efficient [1]. The goal of this project has been to stand as the gap between the student and his alma mater in the act of processing academic transcript as quick as possible so that the students will not be frustrated. Nothing lasts forever, that is true of even the best and most efficient processes. Times change, regulations change, organization preferences change and we believe that paper transcript is at the verge of given way to e-transcript in response to these changes too. For future work, we intend to move to electronic transcript as there is mounting pressure to use them and also to use the Avow Systems as it is the only company that offers a universally accepted solution for securing and delivering electronic documents. For this to be possible, it is expedient for us to develop a deep permanent relationship with the universities that will enable us to move to a higher level of sending official transcripts in an electronic PDF format. The main benefit of the electronic transcripts is the promptness of receipt. This will truly benefits the students, their future institutions, our nation and our educational system at large.

\section{Acknowledgements}

We want to thank the managing director of Electronic learning System LTD, Ikeja Lagos, for giving us the platform and other facilities to carry this project.

\section{REFERENCES}

[1] Báez-Franceschi, S., Le, K., and Velez, D., Web-Based Technologies: Reaching their Ultimate Potential on Restricted Budgets by SIGUCCS '04 Communications of ACM, 336-339, 2004.

[2] Black, T., Secured Electronic Transcripts by in Production AACRAO Technology Conference, Denver, University of Chicago, 2006.

[3] Electronic Transcripts, Online available from https://www.iesabroad.org/IES/Programs/programs.html

[4] Fabunmi, M. and Isah E. A.. Determinant Factors for Planning Students Records Retrieval in Nigerian Universities. Revitalization of African Higher Education, 365-375, 2009

[5] Integritie: Acsent Xtrata Pro, Online available from http://www.integritie.com/kofax

[6] Laurel B. Sanders. High-Volume Scanning and Process Automation for Better, Faster, Smarter Decision Making Optical Image Technology, Inc. 2008.

[7] NUC Database Project (NUCDB), Online available from http://www.nucdb.com/

[8] ReadSoft, Online available from http://www.readsoft.com,

[9] E. J. Egwunyenga, Record Keeping in Universities: Associated Problems and Management Options in South West Geo-Political Zone of Nigeria, International Journal on Educational Science, 1(2): 109-113, 2009.

[10] E. D. Nakpodia, Student's records: Challenges in the management of student personnel in Nigerian tertiary institutions, Prime Research on Education (PRE) Vol. 1(3), pp. 044-049, 2011.

[11] Y. A. Fasasi, School Record Keeping: A Strategy For Management Of Nigerian Secondary Educational Institutions, 2008.

[12] A. A. Olagboye, Introduction to educational management in Nigeria. Ibadan: Daily graphics (Nigeria) Limited, 2004. 
[13] A. B Akporhonor, and Iwhiwhu, B. E., The Management of Staff Records at Delta State University Library, Abraka, Nigeria, Library Philosophy and Practice, 2007.

[14] http://www.epa.gov/records/index.htm
[15] J. B. Daramola., Conservation, preservation and management of public records, national workshop organized for Directors, Deputy and Assistant Director, by the Presidency, Department of Establishment and Management Services. ASCON, Tapo Badagry, 7: 3-11, 1995. 